\title{
A NOVEL APPROACH TOWARDS HANDLING OF BLDC MOTOR DRIVE ALONG WITH FAULTY HALL SENSOR DETECTION AND REMEDIAL STRATEGY
}

\author{
Swathi.K ${ }^{1}$, Nitin Awasthi ${ }^{2}$, Pankaj Sharma ${ }^{3}$ \\ ${ }^{I}$ Student, Electrical and Electronics Department, the Oxford College of Engineering, Bangalore, India \\ ${ }^{2}$ Manager - Technical, APSIS Solutions, Bangalore, India \\ ${ }^{3}$ Design Engineer, Embedded System, APSIS Solutions, Bangalore, India
}

\begin{abstract}
The paper here provides a simple control system to tolerate the fault in BLDC motor resulted due to any failure of Hall Effect sensors. The proposed control system in this paper should be capable of detecting the fault, identify the fault and take remedial actions accordingly. The fault may be due to sensor breakdown or improper connection. In this paper behavior of BLDC motor is studied for Hall Effect sensor breakdown. We are studying the behavior of BLDC motor through simulation and validated first for no fault condition. Then the controller was designed in such a way that it has to detect the fault. Here simulation is done for BLDC motor for sensor breakdown in phase B for two possible faults. The proposed method designed here is to mainly maintain the performance of the motor in good running condition. The simulation results shows the correct performance of Fault tolerant control system which is designed.
\end{abstract}

Keywords: BLDC, Hall Effect, DSPIC30f2010, Fault Tolerant.

\section{INTRODUCTION}

Brushless DC (BLDC) motors are vastly used nowadays in applications that require high reliability, high efficiency, and high power-to-volume ratio. These motors are generally considered to be high performance motors that are capable of providing large amounts of torque over a vast speed range. The name, BLDC is derived from the most commonly used DC motors, which are the brushed DC motors, and they share the same torque and speed performance curve characteristics. The pin point difference between the two is the use of brushes. BLDC motors are void of the brushes, hence the name "brushless DC motors". Theses motors Follow a unique sequencing and switching mechanism and hence must be electronically commutated. Commutation is the act of changing the motor Phase currents at the appropriate times to produce rotational torque. In a Brushed DC motors, the motor assembly consists of physical electrical switching by the means of which the rotor moves. Electrical current through a BLDC motor powers a permanent magnet that causes the motor to move, so no physical commutator is necessary. A BLDC motor is hence highly reliable because it does not have any brushes that can wear out decreasing the longevity of motor. For long term applications, this can be a tremendous benefit. Whenever a motor breaks down or needs to be replaced, the project, or a part of it must be shut down. Hence there is a tradeoff between time and cost. Even though a BLDC motor may cost more than a brushed motor the time required for replacement can be saved and also the quality of work done can be maintained.

BLDC motors may be with or without Hall Effect sensors. Hence the classification Sensor based BLDC and Sensor less BLDC motors. Sensor less BLDC motors are electronically commutated and use three main types of commutation techniques depending on the detection of Back EMF (Electromotive force): trapezoidal commutation, sinusoidal commutation and vectorial commutation. This differentiation is made on the basis of the interconnection of coils in the stator windings to give different types of back EMF [1].

BLDC motors are controlled either using inverters or switching power supply, which results in an AC electric signal to drive the motor. Here AC (alternating current), doesn't refer to a sinusoidal waveform, but is rather a bi-directional current with no restriction on the waveform. In the proposed design a Half Effect sensors based BLDC motor is used. The motor comes with 120 degree phase differences to detect rotor position. The Output of each sensor is high i.e logic ' 1 ' for first 180 electrical degree and is low i.e logic ' 0 ' for the next 180 degree with respect to rotor position. Here the failure of Hall Effect sensors is detected when the sensor value becomes high while the motor is rotating continuously. Various possible faults may happen in a Hall Effect sensor such as flaws in the core, changes in the bias current, change in the magnetic properties of the ferrite core due to the temperature 
variations, changes in the orientation of the induced magnetic field in the sensor. Any of these faults may result to breakdown of the Hall Effect sensors in BLDC motor. Failure of Hall Effect sensor directly affects the applied voltage to BLDC motor and degrades the performance of overall motor drive [2].

The proposed fault tolerant control system should be capable of doing the following tasks i.e. fault detection, fault identification and remedial strategies. In this paper position sensor failure of a three phase (star connection) permanent magnet BLDC motor with the inbuilt Hall Effect sensors is discussed. BLDC motor and three phase VSI drive are shown in Fig.1.

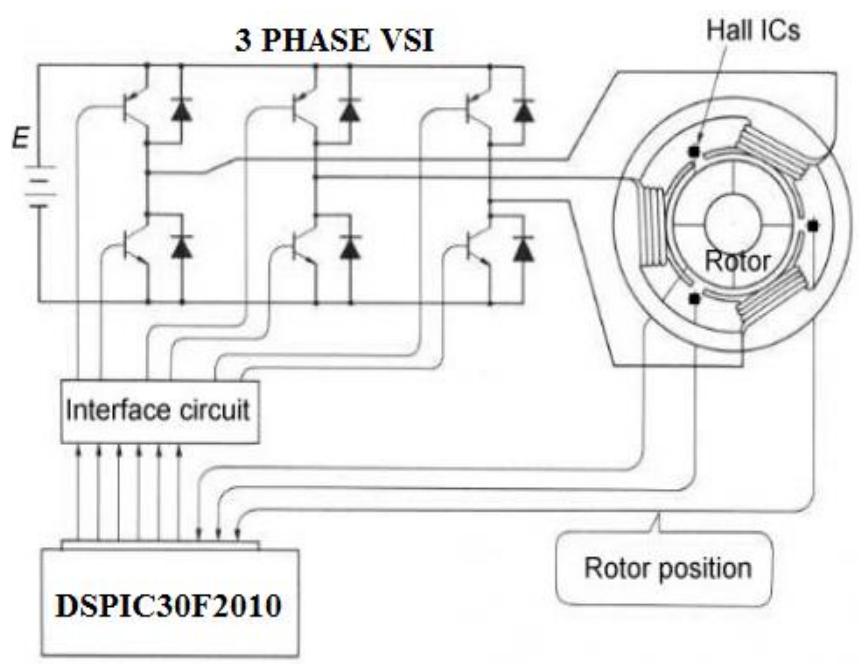

Fig-1 BLDC motor drive system

There are a few research works on Hall Effect sensor failure of BLDC motor specifically for electric vehicle applications. Jeong et al. have presented a control strategy that provides fault tolerance to the major sensor faults which may occur in an interior-permanent-magnet-motor (IPMM)-based electric vehicle propulsion drive system. Position sensors fault is detected through difference between the estimated rotor angle and the actual measured one through a sensor less algorithm based on extended EMF in rotating reference frame. In this approach reconfiguration to sensor less control scheme is introduced to rectify the fault and maintain the proper operation of the motor after fault occurrence is detected.

Complexities of sensorless control scheme and transition Algorithm to senseless control is the main drawbacks of the proposed method. A three phase low voltage BLDC motor is used as a practical test motor to validate simulation results. BLDC motor is simulated in Simulink using Simpower Systems library. The three phase variable source inverter drive of BLDC motor is simulated using MOSFET switches.

\section{CONTROLLING OF BLDC MOTOR}

An electronic Brushless DC Controller (also known as a Driver, or Electronic Speed Controller), replaces the mechanical commutation system utilized by a Brush DC Motor, and is required by most Brushless DC Motors to operate. In a Brushless DC Motor controller, either a Hall Effect Sensor or Back EMF (Electromotive Force) is used to identify the position of the rotor. Understanding the orientation of the rotor is crucial to operating the Brushless DC Motor. The Hall Effect uses three hall sensors within the Brushless DC Motor to help detect the position of the rotor. This method is primarily used in speed detection, positioning, current sensing, and proximity switching. The magnetic field changes in response to the transducer that varies its output voltage. Feedback is created by directly returning a voltage, because the sensor operates as an analogue transducer. The distance between the Hall plate and a known magnetic field can be determined with a group of sensors, and the relative position of the magnet can be deduced. A Hall sensor can act as an on/off switch in a digital mode when combined with circuitry. Back EMF, also known as the CounterElectromotive Force, is caused by a changing electromagnetic field. In a Brushless DC Motor, back EMF is a voltage that occurs where there is motion between the external magnetic field and the armature of the motor. In other words, the voltage is developed in an inductor by an alternating or pulsating current. The polarity of the voltage is constantly the reverse of the input voltage. This method is commonly used to measure the position and speed of the Brushless DC Motor indirectly, and due to the lack of Hall Sensors within the controller, these are often referred to as sensor less controllers. Optical Encoders can also be added to the Brushless DC Motor, allowing both direction and speed to be determined. More precise applications may use Optical Encoders with a third index signal, to determine pulse per revolution. A sensor motor will directly report to the controller, the current position of the motor. Driving a sensor motor requires a look-up table. The current sensor position directly correlates to a commutation pattern for the bridge circuits. In the proposed circuitry a half bridge (as shown in Fig.2) is used as driver for single coil of the motor. The P-type MOSFET consists of two inverters at the input and N-type MOSFET consists of one inverter at the input giving a logic ' 1 ' and ' 1 ' for switch off condition. The inverters are transistor based using IN2222 NPN transistor, IRF9540 as P-type MOSFET and IRF640 as N-type MOSFET. 


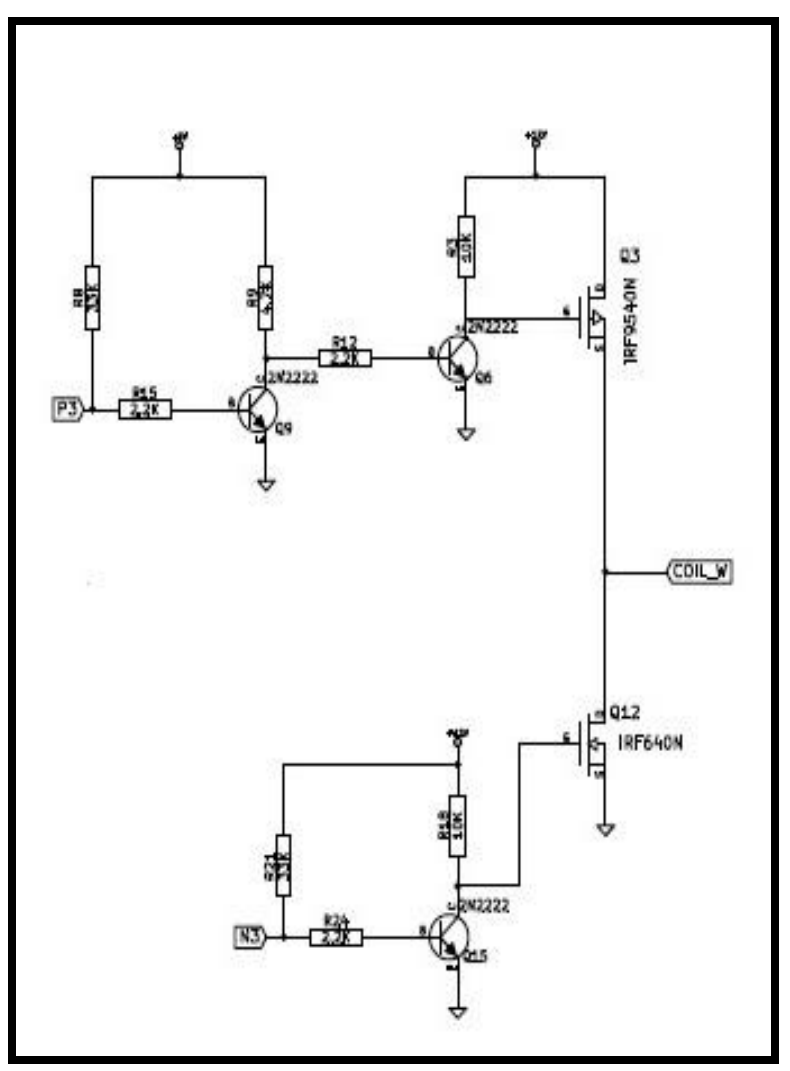

Fig-2 Half Bridge driver

\section{BLOCK DIAGRAM}

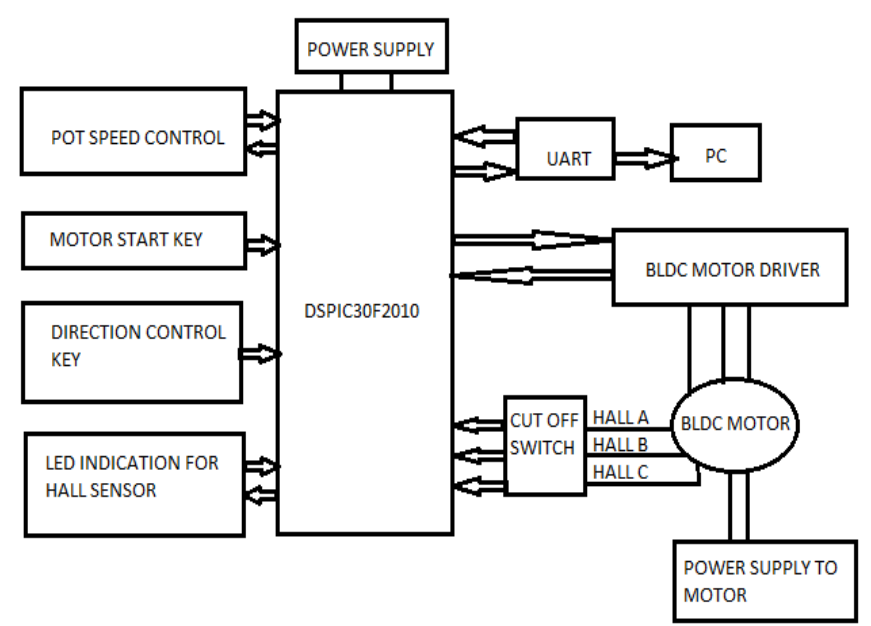

Fig -3 Block diagram

The source to the BLDC motor is AC supply which is converted to DC through VSI. Here six switch 3 legs inverter is used. MOSFET is used as switch in order to control the speed of the motor .The speed of the motor is controlled through pot speed controller which is interfaced to DSP.
Starting of motor and controlling the direction of rotation of motor is controlled using motor start key and direction control key. The output of hall sensors is indicated through LED's interfaced to controller. BLDC motor is connected to the controller through BLDC motor driver i.e. voltage source inverter.

The controller used here is DSPIC30F2010, which is an 28 pin IC. A very good quality of this controller compared to the other controller is, it has in build 10 bit ADC with six input channels. Also it has 6 in built PWM channels. PWM signals are generated by the controller in order to operate the switches in particular sequence. Hall sensor signals are given to the controller through cut-off switches. The hall sensor signals are indicated through LED's interfaced to controller. If the hall sensor fails the cut-off switch will disconnect the particular signal from sensor.

\section{FAULT DIAGNOSIS}

A three phase low voltage BLDC motor is used as a practical test motor to validate simulation results. BLDC motor is simulated in Simulink using SimPower Systems Library. If the position sensor fails, it causes the output signal either to be constant high (logic 1 ) or constant low (logic 0$)$. The output of the position sensor does not change according to the change in the rotor position. Therefore simulation is carried out for both the cases i.e. for both logic 0 and logic 1 . Here simulation is done for the failure of Hall Effect position sensor of phase A. The simulink model is shown in Fig.3.

Electronic commutation is done by decoding the position sensor signals. Decoding rules of Hall Effect signals to choose a proper switching vector of VSI are shown in Table 1.

Table-1: Decoding rules of Hall Effect signal

\begin{tabular}{|l|l|l|l|l|}
\hline $\begin{array}{l}\text { ROTORANGL } \\
\text { E } \\
\text { (ELECTRICA } \\
\text { L DEGREE) }\end{array}$ & $\begin{array}{l}\text { HALL } \\
\text { B }\end{array}$ & $\begin{array}{l}\text { HALL } \\
\text { C }\end{array}$ & $\begin{array}{l}\text { COND } \\
\text { SWITC } \\
\text { HES }\end{array}$ \\
\hline $30-60$ & 1 & 0 & 1 & S1,S4 \\
\hline $90-150$ & 1 & 0 & 0 & S1,S6 \\
\hline $150-210$ & 1 & 1 & 0 & S3,S6 \\
\hline $210-270$ & 0 & 1 & 0 & S3,S2 \\
\hline $270-330$ & 0 & 1 & 1 & S5,S2 \\
\hline $330-30$ & 0 & 0 & 1 & S5,S4 \\
\hline
\end{tabular}




\subsection{Simulink Model}

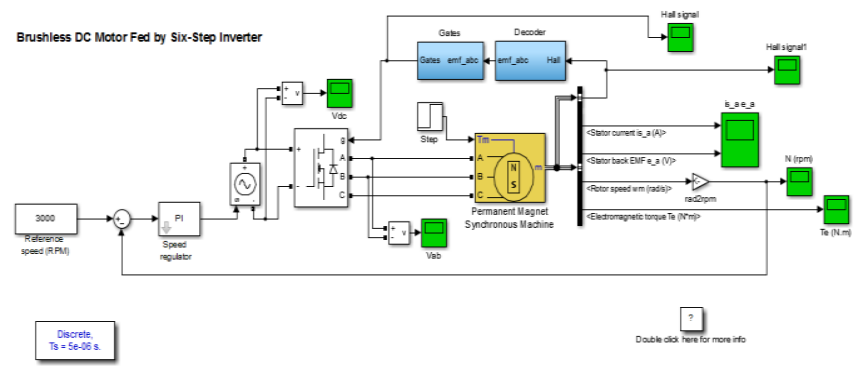

Fig- 3 Simulink model

The addition of Hall signals introduced by (1) is a fault signature for Hall Effect sensors breakdown. Maximum possible value of $H f$ is 2 , where the minimum possible value is 1 (value of $\mathrm{Hf}$ should be 1 or 2) for each specific electrical angle section. If $H f$ value goes over of these limits Hall Effect sensor failure is detected. Hall Effect sensors Fault Flag (HFF) is introduced for sensor fault detection. HFF is set to ' 1 ' if $\mathrm{Hf}$ value is more than 2 (it means that one of the position sensor signals is constant one), HFF is set to '-1' if $H f$ value is less than 1 (it means that one of the position sensor signals is constant zero) and HFF is ' 0 ' in case of no fault. Maximum fault detection time is the time of on electrical rotation of rotor which is quite fast.

$$
\mathrm{H}_{\mathrm{F}=} \mathrm{H}_{\mathrm{A}}+\mathrm{H}_{\mathrm{B}}+\mathrm{H}_{\mathrm{C}}
$$

\subsubsection{Case: 1 Hall Effect Signal is Constant Zero}

BLDC motor is tested for the case 1 where the hall signal output is constant 0 . Hall Effect sensor fault of phase A $\left(\mathrm{H}_{\mathrm{A}}=0\right)$ is applied to BLDC motor running at $3000 \mathrm{RPM}$ speed. Hall Signal at constant 0 is shown is Fig.4.

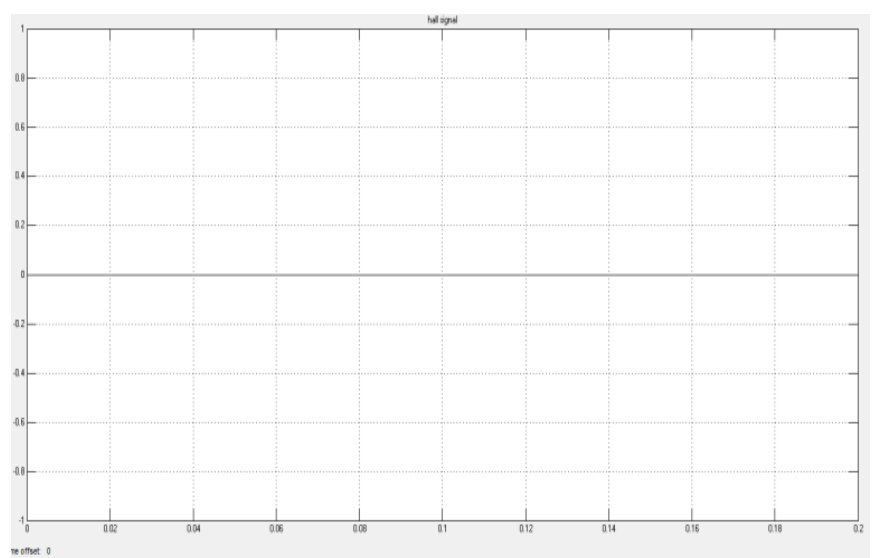

Fig-4: Hall signal at constant zero.

The controller designed in this paper detects the fault in sensor, and then it is capable of generating the signal corresponding to the particular hall sensor as we have taken Hall sensor of Phase A (Hall A).After the signal generated by controller, the hall signal is shown in Fig.4.

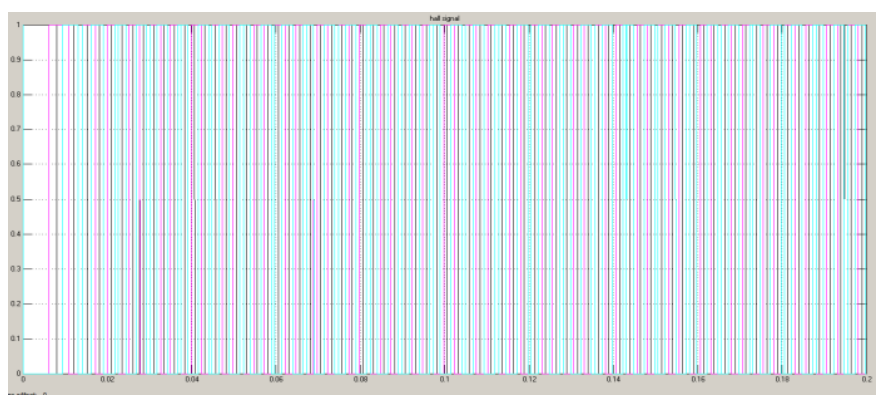

Fig.5. Hall sensor signal after fault is corrected

The speed and torque curve for case 1 is shown in fig.5.
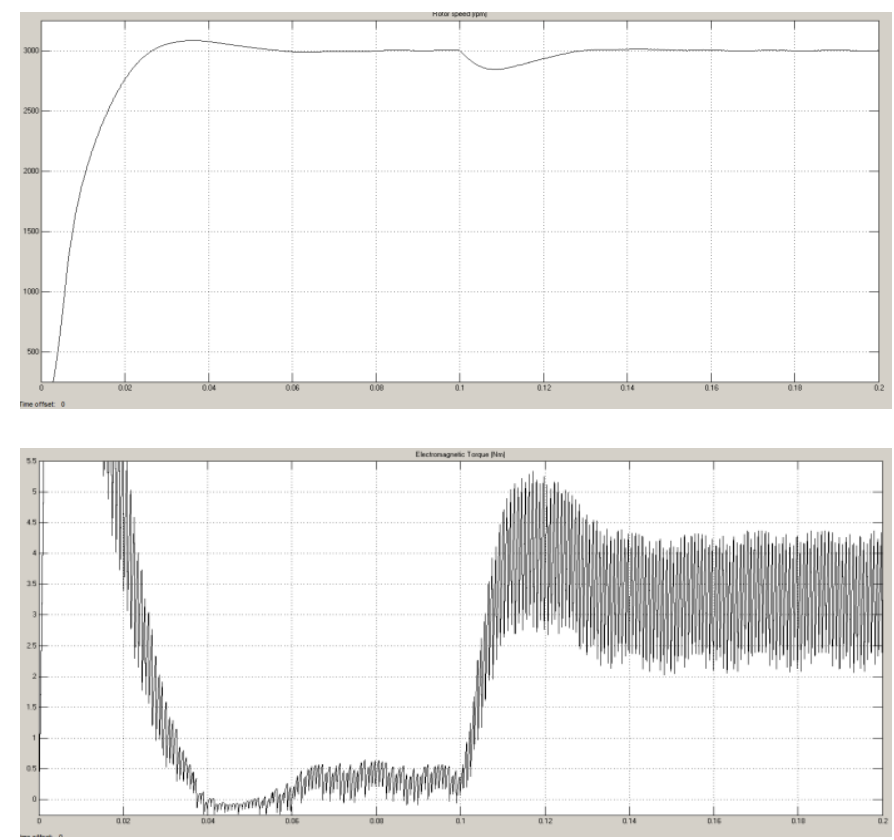

Fig-5: Speed and Torque characteristics $\left(\mathrm{H}_{\mathrm{A}}=0\right)$

Hall Effect sensor failure causes change of the switching signals of VSI and effect directly on the applied line voltage. Effect of various Hall Effect sensors fault on the switching signals of VSI is given in Table II. Switching signals $S 1$ and $S 6$ are constant zero (switches $S 1$ and $S 6$ remain open circuit) for $H A=0$ fault condition. Change of applied voltages cause variation of the stator phase currents of the BLDC motor that effects directly on electrical torque of motor and increases torque ripple. 
Table-2: Sensor fault effect of switching sequence

\begin{tabular}{|l|l|}
\hline FAULT TYPE & OPEN SWITCHES OF VSI \\
\hline $\mathrm{H}_{\mathrm{A}}=0$ & $\mathrm{~S}_{1}, \mathrm{~S}_{6}$ \\
\hline $\mathrm{H}_{\mathrm{A}}=1$ & $\mathrm{~S}_{5}, \mathrm{~S}_{5}$ \\
\hline $\mathrm{H}_{\mathrm{B}}=0$ & $\mathrm{~S}_{3}, \mathrm{~S}_{2}$ \\
\hline $\mathrm{H}_{\mathrm{B}}=1$ & $\mathrm{~S}_{1}, \mathrm{~S}_{4}$ \\
\hline $\mathrm{H}_{\mathrm{C}}=0$ & $\mathrm{~S}_{5}, \mathrm{~S}_{4}$ \\
\hline $\mathrm{H}_{\mathrm{C}}=1$ & $\mathrm{~S}_{3}, \mathrm{~S}_{6}$ \\
\hline
\end{tabular}

\subsubsection{Case 2: Hall Effect Signal is Constant One}

BLDC motor is tested for the case 2 where the hall signal output is constant 1. Hall Effect sensor fault of phase A $\left(\mathrm{H}_{\mathrm{A}}=1\right)$ is applied to BLDC motor running at $3000 \mathrm{RPM}$ speed. Hall Signal at constant 1 is shown is Fig.6.

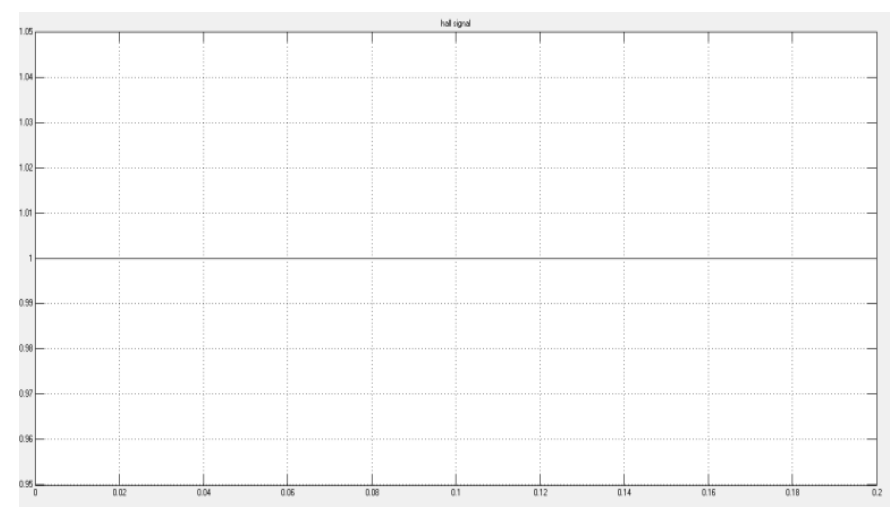

Fig-7: Hall signal is constant one

It can be seen that speed and torque responses of BLDC motor for $H A=1$ are quite similar to the ones for $H A=0$ fault condition. However by checking switching signals of VSI, it can be observed that switches $S 2$ and $S 5$ are constant zero (switches $S 2$ and $S 5$ remain open circuit) after fault occurrence which are not the same as previous fault condition. Therefore applied voltages to the motor are completely different for $H A$ $=1$ fault condition. Hall sensor signal after fault is detected is shown in Fig.7.

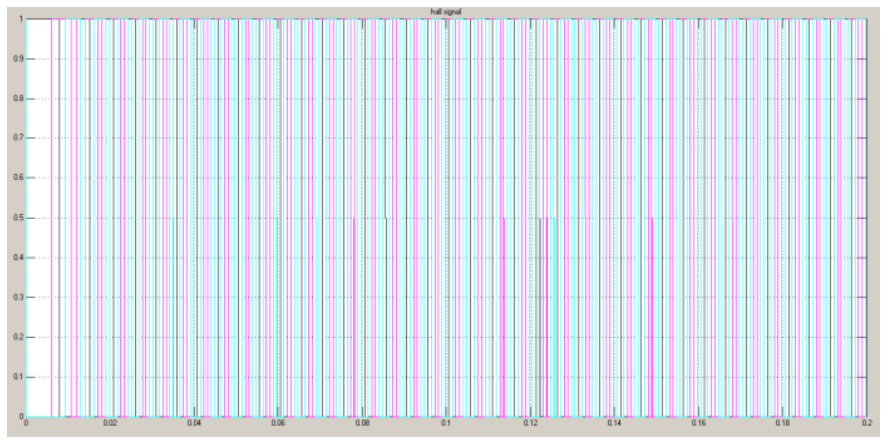

Fig-8: Hall sensor signal after fault is corrected
The speed and torque curve for case 1 is shown in Fig.8.
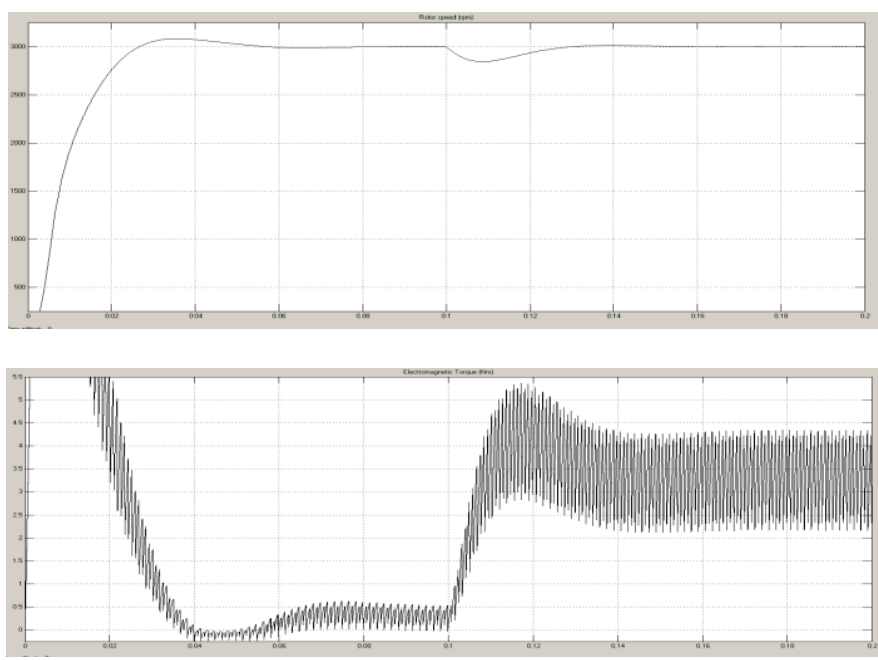

Fig.9. Speed and torque characteristics $\left(\mathrm{H}_{\mathrm{A}}=1\right)$

\section{REMEDIAL STRATERGIES}

After identification of the faulty Hall Effect sensor, corresponding sensor signal is disconnected and is substituted with a generated commutation signal by DSP controller. Commutation signal is generated based on 120 electrical degree phase difference from the other two Hall Effect signals.

\subsection{Flow Chart}

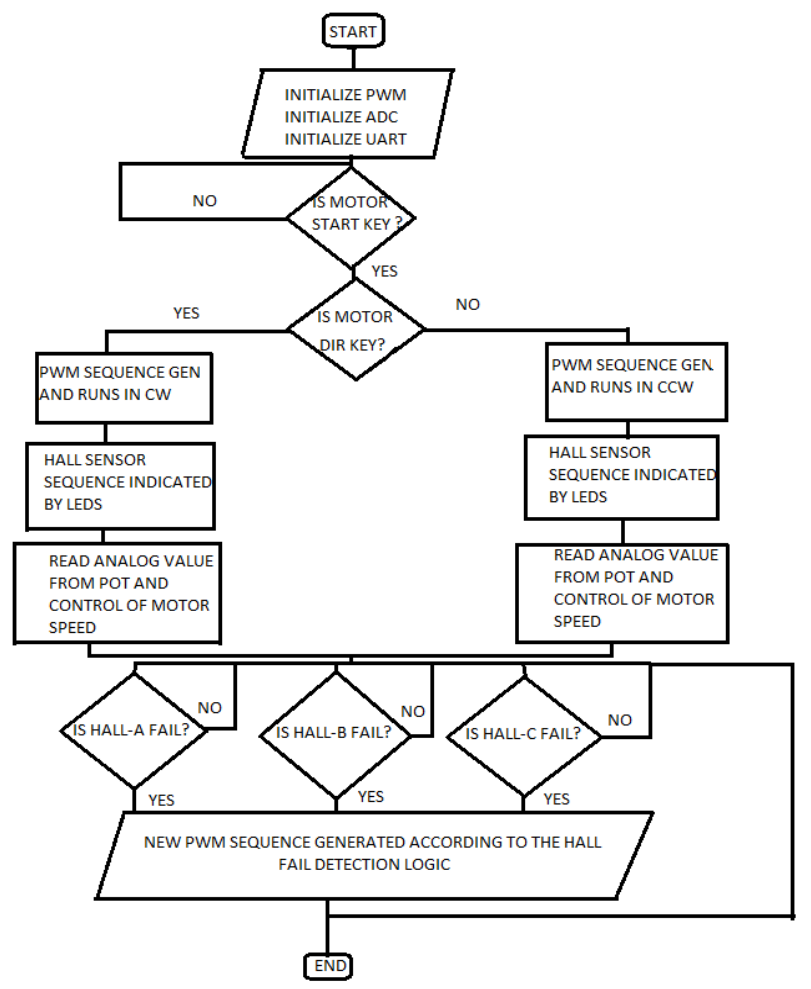




\section{CONCLUSIONS}

Fault tolerant control system for Hall Effect position sensors failure of BLDC motor is discussed in this paper. Behavior of BLDC motor is studied for position sensor failure situations. BLDC motor is implemented on the verified simulation model. A knowledge based table is developed to identify the faulty sensor by analyzing the simulation results. As BLDC motor runs according to the signal generated from hall sensors. If any of the one sensor fails then it directly affects on the performance of the motor. As BLDC motor runs according to the signal generated from hall sensors. If any of the one sensors fails then it directly affects on the performance of the motor. The controller in this project detects, identifies the fault in hall sensors. After identifying the fault, controller will generate the signal corresponding to the faulty sensor output so that it won't affect the performance of the motor. In real time applications, there will be chances of failure of hall sensors so that motor can stop immediately which will create problems. There will be particular sequence in which the switches should operate, so the particular hall signal is generated by controller which will make the motor to run in same speed continuously even if the hall sensor fails and will match the sequence of switches operation.

\section{REFERENCES}

[1]. E Sergio Andrés Reyes Sierra, José Luis Vázquez González, "Switching Techniques for Brushless DC Motors" Electronics, Communications and Computing (CONIELECOMP), 2013 International Conference, vol., no., pp. 162 - 166, 11-13 March 2013.

[2]. A. Tashakori and M. Ektesabi, "A Simple Fault Tolerant Control System for HallEffect Sensors Failure of BLDC Motor" Industrial Electronics and Applications (ICIEA), 2013 8th IEEE Conference, vol,.no, pp. 1011 - 1016, 19-21 June 2013.

[3]. E. Balaban, A. Saxena, P. Bansal, K. Goebel, and S. Curran, "Modeling, detection, and disambiguation of sensor faults for aerospace applications," IEEE Sensors Journal, vol. 9, no. 12, pp. 1907-1917, 2009.

[4]. N. B. Samoylenko, Q. C. Han, and J. Jatskevich, "Dynamic performance of brushless dc motors with unbalanced hall sensors," IEEE Transactions on Energy Conversion, vol. 23, no. 3, pp. 752-763, 2008.

[5]. Y.-S. Jeong, S.-K. Sul, S. Schulz, and N. Patel, "Fault detection and fault-tolerant control of interior permanentmagnet motor drive system for electric vehicle," IEEE Transactions on Industry Applications, vol. 41, no. 1, pp. 4651, 2005.

[6]. L. Wang, J. Liu, and X. Wu, "Fault analysis on driving motors of lunar rover wheels," (Beijing), 20-23 Aug 2011. International Conference on Electrical Machines and Systems, ICEMS 2011

[7]. X.-Q. Liu, H.-Y. Zhang, J. Liu, and J. Yang, "Fault detection and diagnosis of permanent-magnet dc motor based on parameter estimation and neural network," IEEE
Transactions on Industrial Electronics, vol. 47, no. 5,pp. 1021-1030, 2000.

[8].http://en.wikipedia.org/wiki/Brushless_DC_electric_motor 